\title{
Capítulo 9 - De volta para o futuro a visão de cientista no Cinema
}

\author{
Suseli de Paula Vissicaro \\ Márcia Helena Alvim
}

\section{SciELO Books / SciELO Livros / SciELO Libros}

VISSICARO, S.P., and ALVIM, M.H. De volta para o futuro: a visão de cientista no Cinema. In: MOURA, B. A., and FORATO, T. C. M., comps. Histórias das ciências, epistemologia, gênero e arte: ensaios para a formação de professores [online]. São Bernardo do Campo, SP: Editora UFABC, 2017, pp. 183-194. ISBN 978-85-68576-84-7. https://doi.org/10.7476/9788568576847.0010.

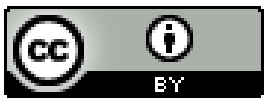

All the contents of this work, except where otherwise noted, is licensed under a Creative Commons Attribution 4.0 International license.

Todo o conteúdo deste trabalho, exceto quando houver ressalva, é publicado sob a licença Creative Commons Atribição $\underline{4.0}$.

Todo el contenido de esta obra, excepto donde se indique lo contrario, está bajo licencia de la licencia $\underline{\text { Creative }}$ Commons Reconocimento 4.0. 


\section{DE VOLTA PARA O FUTURO: A VISÃO DE CIENTISTA NO CINEMA}

Suseli de Paula Vissicaro Márcia Helena Alvim

\section{Introdução}

Vivemos numa sociedade em que a Ciência e a tecnologia se fazem cada vez mais presentes na vida cotidiana, adentrando diariamente nas residências por intermédio dos diferentes meios de comunicação: jornais, revistas, programas de televisão ou de rádio, entre outros. Inúmeros são os assuntos que a envolvem e nos convidam à participação, tanto nas discussões públicas como na tomada de decisões. A Ciência deixou de ser um assunto meramente de cientistas.

A facilidade do acesso à informação e o fato de estarmos conectados 24 horas por dia na internet nos permitem, "[...] em qualquer local, recolher informação sobre qualquer assunto em poucos minutos, mudaram de fato a nossa forma de viver" (GOLDSCHMIDT; GOLDSCHMIDT JÚNIOR; LORETO, 2014, p. 134). Nesse acesso irrestrito à informação, diferentes visões de Ciência e de cientista nos são apresentadas pelas diferentes mídias. "Algumas destas visões se afastam da prática científica, 
mas encontram-se incorporadas ao imaginário científico popular", influenciando as práticas educativas, podendo transmitir [...] visões da Ciência que se afastam notoriamente da forma como se constrói o conhecimento científico" (GOLDSCHMIDT; GOLDSCHMIDT JÚNIOR; LORETO, 2014, p. 134).

A visão tradicional sobre a Ciência comumente veiculada, sobretudo nos materiais didáticos, a apresenta como uma atividade neutra, atemporal e livre de pressões de natureza política, econômica ou social. Numa certa caricatura, uma Ciência feita por alguns poucos gênios, que buscam a verdade e utilizam um método científico, único e infalível.

No entanto, essa visão vem sofrendo modificações a partir dos estudos intensificados na década de 1970 (atualmente desdobrados e conhecidos como "Estudos Sociais da Ciência e da Tecnologia"), que situam a Ciência como um produto cultural, resultante de um processo, em outras palavras, ciência como cultura, uma "[...] construção humana sobre os fenômenos do mundo natural a partir de elementos de seu universo cultural, possuindo uma relação dialógica com a sociedade em que é produzida, pois a Ciência sofre e exerce impactos sócio-político-econômicos e culturais na mesma" (ALVIM, 2012, p. 3).

Essa visão tradicional persiste, especialmente no ambiente escolar e nas mídias, influenciando a percepção pública sobre a Ciência e o cientista, como pode ser observado nos filmes e nas falas dos alunos, quando o tema é abordado. A este respeito, Carretero (1993 apud GOLDSCHMIDT; GOLDSCHMIDT JÚNIOR; LORETO, 2014, p. 134-135) ressalta que "[...] os alunos trazem para a sala de aula teorias e explicações sobre o seu cotidiano oriundas de várias fontes, tais como conversas com amigos, familiares, mídia, contextos social e cultural, entre outras". E completa, destacando que essas teorias e explicações, 
além do caráter espontâneo que apresentam, são "extremamente resistentes".

Acerca dessas teorias e explicações trazidas para a sala de aula, diferentes estudos, entre eles o de Gil-Pérez et al. (2001, p. 126), pontuam que não apenas alunos, mas também professores, apresentam certas visões, denominadas pelo autor como deformadas, acerca da Ciência, do trabalho científico e de como se "constroem e se produzem conhecimentos científicos". Essas visões deformadas, quando transmitidas pelo professor, contribuem e reforçam a visão presente nas diferentes esferas e mídias, contudo, convém destacar que elas nem sempre foram as mesmas. Estudos apontam que as visões sobre a Ciência e o cientista em filmes cinematográficos variam, refletindo o contexto no qual os mesmos foram produzidos, como veremos no presente artigo.

Deste modo, este texto irá apresentar uma análise sobre a visão de cientista e Ciência veiculada no filme De volta para o futuro, apresentando possibilidades pedagógicas para professores de Ciências, numa perspectiva de educação científica crítica e reflexiva por meio de discussões sobre a natureza da Ciência em filmes cinematográficos.

\section{Ciência e Cinema}

As relações entre a Ciência e o Cinema são antigas, sendo atribuído a Thomas Alva Edson (1847-1931) a iniciativa de juntar os conhecimentos científicos existentes no final do século XIX "para criar, em seu laboratório, o cinetoscópio ${ }^{1}$ Edson"

1 O cinetoscópio de Edson era "uma espécie de caixa metálica, com uma fonte de luz e um visor, através do qual uma primitiva fita passava à razão de 46 imagens por segundo, gerando a sensação de movimento" (BARCA, 2005, p. 32). 
(BARCA, 2005, p. 32), antes mesmo da invenção do cinematógrafo $^{2}$ pelos irmãos Lumiére. O primeiro filme de ficção científica da história, o curta metragem Le Voyage dans la lune (Viagem à Lua), de 1902, de Georges Méliès, foi também a primeira obra cinematográfica em que apareceram "[...] as primeiras representações de cientistas no cinema, ainda que inspiradas em um romance de ficção" de Júlio Verne (CUNHA; GIORDAN, 2009, p. 10). Misturando animação, comédia e curiosidade científica, Méliès apresenta cientistas semelhantes a magos e feiticeiros (BARCA, 2005). Depois deste, muitos outros filmes "[...] foram produzidos e contribuíram para povoar o imaginário das pessoas, colaborando para construção de uma imagem pública da Ciência e dos cientistas" (CUNHA; GIORDAN, 2009, p. 10), servindo como veículo de divulgação dos avanços da Ciência (OLIVEIRA, 2006).

Segundo Barca (2005, p. 33), “[...] a maioria da população forma suas impressões sobre a Ciência e os cientistas a partir do que veem na mídia, seja nos noticiários, seja em programas de entretenimento, como filmes e novelas". Isso porque "[...] o modo como cada filme é concebido e a época em que ele é realizado têm reflexos diretos na forma como o indivíduo produz os significados e, portanto, na formação de seu pensamento" (CUNHA; GIORDAN, 2009, p. 14). Em outras palavras, o filme reflete em sua concepção o contexto no qual foi produzido, "[...] transmitindo a visão da sociedade ou, pelo menos, de um determinado segmento da sociedade sobre os temas que aborda" (BARCA, 2005, p. 33), e que influenciam a percepção do indivíduo.

Mas, quais seriam essas visões de Ciência e cientista veiculadas pelo Cinema?

2 O cinematógrafo era uma mistura de máquina de filmar e projetor de Cinema. 
No estudo realizado pelo sociólogo Andrew Tudor (1989) e publicado no livro Monsters and mad scientists: a cultural history of horror movie (Monstros e cientistas loucos: uma história cultural dos filmes de terror), é possível observar que a imagem do cientista se modifica entre as décadas de 1930 e 1980 . Segundo o sociólogo (1989 apud BARCA, 2005, p. 33), de mil filmes analisados, em 264, "[...] a ciência é a principal promotora de ameaças à humanidade". Em outros 169 filmes a origem de todos os problemas seria um cientista louco, e "[...] nos 95 restantes, as ameaças não são ocasionadas pela ação direta do cientista, mas são consequências das investigações e descobertas científicas" (BARCA, 2005, p. 33).

Em outras palavras, as imagens dos cientistas variaram do louco aos "[...] homens vivos, inteligentes e respeitáveis produtores de conhecimento por trás dos feitos militares", até papéis secundários, nos quais os acidentes ganham destaque. De acordo com Tudor (apud BARCA, 2005, p. 33), “[...] demorou cinquenta anos para que a maioria das pessoas deixasse de idealizar e ao mesmo tempo temer o cientista, como se fosse uma espécie de bruxo". Assim, a década de 1980 é marcada por uma nova visão de cientista, na qual este assume o papel de herói e aventureiro "[...] que utiliza seus conhecimentos para resolver mistérios e salvar o mundo. É também o professor fascinante que desperta paixões nos alunos, principalmente nas alunas" (BARCA, 2005, p. 36).

Foi nesse período que surgiu a trilogia De volta para o futuro, "[...] que nos mostrava um novo tempo cheio de máquinas e hologramas e nos fazia pensar sobre o futuro e o passado por meio de universos paralelos: um encantamento aos adolescentes e jovens da época" (BARBOSA; BAZZO, 2013, p. 150). Neste filme, o cientista é apresentado como genial e atrapalhado, que 
descobriu sozinho o segredo do tempo e "[...] que faz experiências divertidas e bastante arriscadas, mas que sempre aparece no momento certo para evitar consequências de maior gravidade para o seu jovem amigo e cobaia" (BARCA, 2005, p. 36). Esse filme do diretor Robert Zemeckis entrou para o rol das comédias de maior bilheteria do Cinema, ao mesmo tempo em que reforçava a ideia do cientista louco e genial.

A exemplo do que aconteceu com a literatura, a ficção científica em filme se tornou um gênero popular. Os cientistas conquistaram a simpatia do público como heróis aloprados e divertidos, sempre empenhados em novas experiências, que quase nunca dão certo. (BARCA, 2005, p. 36).

A pesquisa de Tudor, realizada com uma amostragem de mil filmes, demonstra a diversidade de papéis que representaram o cientista no Cinema num determinado período de tempo. Acreditamos que tais filmes certamente influenciaram e ainda influenciam a percepção pública sobre a Ciência e também as representações da sociedade sobre os cientistas. No presente capítulo, não buscamos aprofundar a análise sobre a visão de Ciência e cientista em cada período como Tudor faz; mas, procuramos reconstruir o contexto no qual o filme De volta para o futuro (1985) foi feito e seu potencial para analisarmos a visão de Ciência e cientista veiculada nos filmes cinematográficos.

\section{De volta para o futuro e a percepção sobre Ciência e cientista}

O filme narra a história de Marty McFly, um típico adolescente americano que frequenta o ensino médio, e sua amizade 
com o Dr. Brown, um excêntrico cientista. Ao chegar pela quarta vez atrasado à escola, Marty ouve do diretor que o Dr. Emmet Brown (Doc) é perigoso, um maluco, e o alerta para os problemas que poderia ter ao ser amigo do doutor.

No filme, o Dr. Brown pede que Marty o encontre no estacionamento do shopping da cidade e que leve a câmera de vídeo. Ao chegar ao local combinado, Marty vê Doc saindo de um caminhão com um DeLorean, numa versão modificada e futurista, com sua última experiência. Nesta cena, Doc realiza a experiência de viagem no tempo utilizando o carro. Tudo é registrado pelos olhos atentos de Marty, que filma todo o evento, sem acreditar no que vê. Questionado sobre o que aconteceu com o carro e o cachorro Einstein, Doc explica que ele (o cachorro) é o primeiro viajante no tempo, indo para o futuro, e que o carro é uma máquina de viagem no tempo.

Na sequência, com o retorno do cão, Doc explica a Marty o que aconteceu e como funciona. Nesta cena, o cientista aparece usando um macacão branco, com o símbolo da radioatividade estampado nas costas e usando um cinto com algumas ferramentas e seu cabelo aparece despenteado. No filme, a data 5 de novembro de 1955 é importante para a Ciência, pois, segundo Doc, foi o dia em que ele inventou um dispositivo que possibilitaria a viagem no tempo, após bater a cabeça e ter uma visão: o "capacitador de fluxo", que demorou 30 anos para ser transformado em realidade. É um carro elétrico, mas que usa plutônio para gerar a eletricidade necessária para funcionar, por meio de uma reação nuclear.

Explicações à parte, o filme continua, com Marty entrando no carro para fugir dos líbios, de quem Doc roubou o plutônio que seria utilizado para fazer uma bomba, e chegando à referida data, novembro de 1955, conhecendo seus futuros pais e seu 
amigo cientista. Nesse pequeno trecho, podemos perceber a visão de cientista veiculada pelo filme: temos o cientista inventor, com ideias futuristas, mas apresentado como louco, que inventa a viagem no tempo após bater sua cabeça. Suas roupas e sua aparência reforçam essa visão.

Traçando um paralelo com os dias atuais, esta imagem de cientista nos filmes comerciais está perdendo espaço, mas ela ainda persiste nos filmes e animações infantis, como em Meu Malvado favorito ou Tá chovendo hambúrguer, para citarmos alguns exemplos. Tais filmes associam a imagem do cientista ao pesquisador do sexo masculino, sempre inteligente, que utiliza a criatividade para resolver problemas cotidianos ou mesmo realizar certos feitos tidos como impossíveis, relacionando Ciência a laboratórios e experimentos.

Os cientistas no Cinema são sempre retratados como personalidades solitárias, como o Dr. Brown, o que perpetua a ideia de

[...] uma visão individualista da Ciência, em que os conhecimentos científicos aparecem como obras de gênios isolados, sendo exclusivos do sexo masculino. [...]. Essa imagem estereotipada do cientista e da Ciência veiculada na mídia, [...] pode gerar um afastamento e certo preconceito por parte dos alunos em relação à disciplina e ao professor de Ciências, o que acaba por dificultar o trabalho de construção do conhecimento científico em sala de aula. (GOLDSCHMIDT; GOLDSCHMIDT JÚNIOR; LORETO, 2014, p. 137).

Para Cachapuz (2005 apud GOLDSCHMIDT; GOLDSCHMIDT JÚNIOR; LORETO, 2014, p. 137), essas visões empobrecidas acabam por criar o desinteresse e até mesmo a rejeição a este conhecimento por parte do aluno, convertendo-se em 
obstáculos à aprendizagem, cabendo ao professor, "[...] a tarefa de questionar as diversas visões de Ciências que são veiculadas nos meios de comunicação, de forma a levar o aluno à reflexão sobre o papel da ciência em sua vida".

A interação e mediação do professor são fundamentais nesse processo de reflexão e desconstrução, objetivando promover uma aprendizagem significativa sobre o tema. Isto porque,

A educação em ciências enfrenta um desafio contemporâneo, ela deve contribuir para que o cidadão estabeleça uma relação crítica com a ciência e a tecnologia, relação que seja um antídoto ao ceticismo que idolatra e mitifica a ciência [...] Este desafio guarda correlação com a necessidade de que esse cidadão compreenda a ciência como parte do legado cultural. (MESQUITA, 2008 apud SILVA et al., 2002, p. 2).

Dessa forma, precisamos problematizar e apresentar visões mais próximas da realidade da atividade do cientista e de como este realiza suas pesquisas e onde as faz, haja vista que diferentes cientistas trabalham em diferentes locais, nem sempre em laboratórios.

Por fim, outros pontos ao longo do filme podem ser problematizados, mas, de maneira geral, a película reforça uma imagem tradicional da atividade cientifica e da genialidade do cientista, como um homem à frente de seu tempo e maluco, simultaneamente. Por isso, o filme pode se apresentar como uma excelente oportunidade didática ao professor, por meio de atividades orientadas após a exibição do filme ou promovendo debates a partir de extratos selecionados. As propostas didáticas são variadas e, neste texto, não pretendemos discuti-las, mas sim indicar caminhos para o uso pedagógico desse importante veículo reflexivo. 


\section{Considerações finais}

Como obra artística, não temos a pretensão de ensinar didaticamente conteúdos pré-estabelecidos através dos filmes, mas problematizá-los. Além de ser, segundo Braga, Guerra e Reis (2007, p. 7), "um ponto de partida gerador de debates e aprendizagens de múltiplos conteúdos", o filme também pode ser utilizado como uma nova forma de abordagem das disciplinas.

Mais do que um suporte, os filmes comerciais podem constituir-se em importantes elementos para discussão acerca da ciência e da atividade científica, por apresentarem concepções que podem ser problematizadas, principalmente sobre o cientista, que aparece retratado de maneira sempre estereotipada ao longo da história do Cinema. Tais concepções refletem a visão da sociedade ou de determinado grupo sobre o tema, bem como o contexto em que foi feito, influenciando na percepção do indivíduo e na imagem que este constrói, ainda que o objetivo dos filmes comerciais seja o entretenimento e o lazer.

Visões tradicionais influenciam diretamente na percepção pública sobre a Ciência, e cabe ao professor conhecer essas visões e mediar discussões que visem desconstruí-las, colaborando para a "[...] decodificação dos interesses sociais presentes na construção das imagens fílmicas, abrindo horizontes para a sua ressignificação" (BARBOSA; BAZZO, 2013, p. 152). Assim, ao promovermos ações pedagógicas que busquem analisar essas visões, contribuímos para a formação crítica e para uma educação que privilegie a cidadania e a reflexão.

\section{Referências}

ALVIM, Marcia H. História das Ciências e Ensino de Ciências: potencialidades para uma educação cidadã. In: SEMINARIO 
IBÉRICO, 7.; SEMINARIO IBEROAMERICANO CTS, 3. "CIENCIA, TECNOLOGÍA Y SOCIEDAD EN EL FUTURO DE LA ENSEÑANZA DE LAS CIENCIAS", 28-30 sep. 2012, Madri. Anais... Madri: AECID, 2012. p. 1-8.

BARBOSA, Leila Cristina Aoyama; BAZZO, Walter Antonio. O uso de documentários para o debate ciência-tecnologia-sociedade (CTS) em sala de aula. Revista Ensaio, Belo Horizonte, v. 15, n. 3 , p. 149-161, set./dez. 2013.

BARCA, Lacy. As múltiplas imagens do cientista no cinema. Comunicação \& Educação, ano X, n. 1, p. 31-39, jan./abr. 2005.

BRAGA, Marco; GUERRA, Andréia; REIS, José Cláudio. Cinema e História da Ciência na formação de professores. In: Simpósio Nacional de Ensino de Física, 16., 24-28 jan. 2005, Rio de Janeiro. Anais eletrônicos... Rio de Janeiro: Sociedade Brasileira de Física, 2005. Disponível em: <http://www.sbf1.sbfisica.org.br/eventos/ snef/xvii/sys/resumos/T0147-1.pdf>. Acesso em: 8 jan. 2016.

CUNHA, Marcia Borin da; GIORDAN, Marcelo. A imagem da ciência no cinema. Química Nova na Escola, v. 31, n. 1, p. 9-17, 2009.

DE VOLTA para o futuro. Gênero: Ficção Científica. Direção: Robert Zemeckis. Roteiro: Bob Gale, Robert Zemeckis. Elenco: Billy Zane, Casey Siemaszko, Christopher Lloyd, Claudia Wells, Courtney Gains, Crispin Glover, Cristen Kauffman, David Harold Brown, Donald Fullilove, Elsa Raven, Frances Lee McCain, Gary Riley, George "Buck" Flower, George DiCenzo, Granville "Danny" Young, Harry Waters Jr., Ivy Bethune, J. J. Cohen, James Tolkan, Jamie Abbott, Jason Hervey, Jason Marin, Jeff O'Haco, Johnny Green, Karen Petrasek, Katherine Britton, Lea Thompson, Lee 
Brownfield, Lisa Freeman, Lloyd L. Tolbert, Maia Brewton, Marc McClure, Michael J. Fox, Norman Alden, Paul Hanson, Read Morgan, Richard L. Duran, Robert DeLapp, Robert Krantz, Sachi Parker, Thomas F. Wilson, Tommy Thomas, Wendie Jo Sperber, Will Hare. Produção: Bob Gale, Neil Canton. Fotografia: Dean Cundey. Trilha Sonora: Alan Silvestri. Duração: 116 min. Ano: 1985. País: Estados Unidos. Cor: Colorido. Estúdio: Amblin Entertainment; Universal Pictures. Classificação: Livre.

GIL-PÉREZ, Daniel; MONTORO, Isabel Fernández; ALÍS, Jaime Carrascosa; CACHAPUZ, António; PRAIA, João Praia. Para uma imagem não deformada do trabalho científico. Ciência \& Educação, v. 7, n. 2, p. 125-153, 2001.

GOLDSCHMIDT, Andrea Inês; GOLDSCHMIDT JÚNIOR, José Luiz; LORETO, Élgion Lúcio da Silva. Concepções referentes à Ciência e aos cientistas entre alunos de anos iniciais e alunos em formação docente. Contexto \& Educação, ano 29, n. 92, p. 132-64, 2014.

OLIVEIRA, Bernardo Jefferson. Cinema e imaginário científico. História, Ciências, Saúde-Manguinhos, v. 13 (suplemento), p. 133-150, out. 2006.

SILVA, Kathya Rogéria; GASPARRINI, Lázaro José; SILVA, Lilian Rogéria; CUNHA, Marcia Borin. Percepções de cientista no filme "Os Smurfs": uma experiência em sala de aula. In: ENCONTRO NACIONAL DE ENSINO DE QUÍMICA, 16., Salvador, 17-20 jul. 2012. Anais eletrônicos... Salvador: UFBA, 2012. Disponível em: <http://www.portalseer.ufba.br/index.php/anaiseneq2012/ article/view/7442>. Acesso em: 10 mar. 2016. 